\title{
Effects of Mixing on Ammonia Oxidation in Combustion Environments at Intermediate Temperatures
}

\author{
Joseph F. Grcar ${ }^{\mathrm{a}}$, Peter Glarborg ${ }^{\mathrm{b}}$, John B. Bell ${ }^{\mathrm{a}}$, \\ Marcus S. Day ${ }^{\mathrm{a}}$, Antonio Loren ${ }^{\mathrm{b}}$, Anker D. Jensen ${ }^{\mathrm{b}}$ \\ ${ }^{a}$ Center for Computational Sciences and Engineering \\ Lawrence Berkeley National Laboratory \\ Berkeley, California, 94720 USA \\ ${ }^{\mathrm{b}}$ Department of Chemical Engineering \\ Technical University of Denmark \\ 2800 Lyngby, Denmark
}
corresponding author: Joseph F. Grcar
address: Lawrence Berkeley National Laboratory
Mail Stop 50A-1148
One Cyclotron Road
Berkeley, CA 94720-8142 USA
fax: (510) 486-6900
email: jfgrcar@lbl.gov

paper ID number: PID28783

running title: Effects of Mixing on Ammonia Oxidation

To appear in: Proceedings of the Combustion Institute. volume 30, 2004. 


\begin{abstract}
Ammonia often occurs in combustion gases as a product of fuel-nitrogen. Since either NO or $\mathrm{N}_{2}$ may predominate as the product of ammonia oxidation, there is considerable interest in understanding the factors responsible for selecting the final products. In flames the selectivity is known to depend on whether the reaction zones are premixed or non-premixed. This paper reports on a combined experimental and modeling investigation of ammonia chemistry in a hot combustion environment that is below flame temperatures, such as in post combustion gases. Experiments that mix highly diluted ammonia-methane and oxygen-water streams are interpreted in terms of a plug-flow model, a simplified mixing reactor model, and a two-dimensional direct numerical simulation. The study finds that the final products of ammonia oxidation remain sensitive to mixing even at temperatures below those of self-sustaining flames. At low temperatures ammonia oxidation occurs in a premixed reaction zone, but at sufficiently high temperatures a nonpremixed reaction zone may develop that produces significantly less NO than the equivalent premixed system. A direct numerical simulation is required to predict the behavior over the full range of conditions investigated experimentally, while a simplified mixing reactor model captures the essential features as long as the radial gradients are not too steep.
\end{abstract}

\title{
Keywords
}

ammonia chemistry, fuel nitrogen, mixing 


\section{Introduction}

In many combustion systems ammonia occurs in the gas-phase as a major fuel-nitrogen compound. Ammonia is a primary volatile product of organic nitrogen compounds in biomass fuels and may also be formed in significant amounts during coal pyrolysis [1]. The oxidation of $\mathrm{NH}_{3}$ is characterized by a selectivity in the reaction pathways: it may be oxidized to $\mathrm{NO}$ by reaction with $\mathrm{O}_{2}$ (undesired), or it may react with $\mathrm{NO}$ to form $\mathrm{N}_{2}$ (the desired reaction). The fact that $\mathrm{NH}_{3}$ under favorable conditions may react selectively with $\mathrm{NO}$ has prompted the use of ammonia as an additive to control $\mathrm{NO}_{x}$ in the Thermal De- $\mathrm{NO}_{x}$ process $[2,3]$.

Due to the importance of ammonia as a source of fuel-NO in combustion processes there has been considerable interest in understanding how to minimize NO formation. The selectivity in $\mathrm{NH}_{3}$ oxidation towards $\mathrm{NO}$ or $\mathrm{N}_{2}$ depends mainly on the temperature and gas composition [4], but the mixing of reactants also is conceivably important because changes in the local conditions may favor different reaction paths. It has been observed that mixing governs the selection of the final products from oxidation of trace amounts of ammonia in flames [1,5]. For premixed flames the conversion efficiency of $\mathrm{NH}_{3}$ to $\mathrm{NO}$ is largely independent of the level of $\mathrm{NH}_{3}$ seeding, whereas in nonpremixed flames the conversion efficiency declines with greater seeding. Sullivan et al. [6] found that increased ammonia seeding of nonpremixed flames accelerates mainly reactions among two nitrogenous species. Many bimolecular nitrogen reactions consume $\mathrm{NO}$ and produce $\mathrm{N}_{2}$ thereby altering the $\mathrm{NO}: \mathrm{N}_{2}$ ratio of the final products. This effect depends on the fluid dynamics of nonpremixed flames; in premixed flames which involve the same reactions the sensitivity of the NO selectivity towards the fuel-N level is much smaller $[1,5]$.

This paper examines the conversion of ammonia to NO in an environment that is below flame temperatures as would be encountered in post combustion gases. Experiments with commingling highly diluted ammonia-methane and oxygen-water streams are performed in a laminar, co-flow reactor under nearly isothermal conditions. The experimental results are interpreted in terms of a plug-flow model, a simplified mixing reactor model, and a two-dimensional direct numerical simulation. 


\section{Experiment}

The experimental setup has been used previously to characterize mixing effects in the Thermal De-NO $\mathrm{NO}_{x}$ process [7]. Briefly, the reactor consists of a vertical quartz tube with upwardly flowing gases. Fuel enters through an inner tube surrounded by a concentric oxidizer co-flow. Figure 1 shows the reactor dimensions. The tubes extend $33 \mathrm{~cm}$ below the mixing point to fully develop laminar velocity profiles. An electrically heated oven houses the reactor in a nearly isothermal environment $( \pm 13 \mathrm{~K})$. Continuous gas analyzers measure the concentrations of $\mathrm{NO}, \mathrm{CO}, \mathrm{CO}_{2}$ and $\mathrm{O}_{2}( \pm 3 \%)$ in the outflow. Data is acquired for a range of temperatures and fuel/oxidizer volumetric flow ratios.

Table 1 lists the composition of the inflow streams by mole fraction of the total flow. The reactants are highly diluted in nitrogen to minimize the temperature increase from reactions. The total amount of nitrogen (about $94 \%$ by volume) is apportioned between the streams to select different fuel/oxidizer $(\mathrm{F} / \mathrm{O})$ volumetric flow ratios, thereby changing how the streams mix inside the reactor. Since the total inflow is $2 \mathrm{~L} / \mathrm{min}$ at standard temperature and pressure, species always enter at the same molar rate. The experiment thus emphasizes the effects of mixing on the chemistry of a single, fixed dosage of reactants.

In the present experiments the reactor operates in three fuel/oxidizer flow ratios of 1:3, 1:1, and 3:1, at temperatures ranging from 900 to $1500 \mathrm{~K}$ in steps of $25 \mathrm{~K}$, and at a pressure of 1.2 (bar). Figure 2 displays the concentration of NO measured in the outflow. The figure also displays predictions from the three models.

\section{Simulation Methodology}

Simulations are needed to understand the operating modes of the reactor because the hot environment in which the apparatus is confined makes it difficult to observe the experiment directly. As a reference calculation for a completely premixed system, we performed plug-flow modeling using SENKIN [8]. A low Mach number model provides a full description of the two-dimensional chemically reacting flow. Finally, a Zwietering mixing reactor model offers a simplified assessment of the effect of mixing on the chemistry. All the simulations model the chemistry using the 65 species, 447 reaction mechanism of Glarborg et al. [9] for ammonia and methane oxidation. 
There have been many years of work modeling nitrogen chemistry in combustion environments. Our mechanism in particular draws on [10] [11] [12]. Probably the first look at mixing effects on NO using rigorous kinetics and transport models was [13]. Fully 2D laminar flame calculations with nitrogen chemistry are more recent [14].

\section{Plug-Flow Calculation}

There is only one plug-flow condition for each temperature because the species always have the same molar inflow rate. The nominal residence time used for the SENKIN [8] calculation is 1274/T, i.e., $1.274 \mathrm{~s}$ at $1000 \mathrm{~K}$.

Figure 2's comparison between experiment and the plug-flow model reveals that the reactor has two modes of operation. When there is good agreement between the measurements and the plug-flow predictions, then the reactor contains a premixed reaction zone. This mode is selected both by the temperature and the flow ratio. At temperatures higher than a crossing point, which is slightly warmer for higher flow ratios, the NO measurements depart from the plug-flow predictions. Evidently a complex interaction between the characteristics of the flow and the oxidation chemistry takes place. A detailed modeling of the mixing/chemistry interaction is required to understand this behavior.

\section{The Two-Dimensional Model}

\subsection{Description}

A two-dimensional simulation of the reactor is performed using the low Mach number approximation of Majda and Sethian [15] and Rehm and Baum [16]. The differential equations are discretized and solved using the adaptive mesh refinement (AMR) algorithms of Day and Bell [17]. Reaction terms and transport properties are evaluated using CHEMKIN [18] [19]. This combination of models with the Glarborg et al. mechanism has been successfully applied to study nitrogen chemistry in methane-air diffusion flames [6] [20].

Since the flow is laminar and believed to be axisymmetric, it suffices to consider a computational domain consisting of the $1.25 \times 25.0 \mathrm{~cm}^{2}$ radial-axial plane shown in Fig. 1 . The velocity profiles 
of the incoming fuel and oxidizer streams are assumed to be fully developed laminar pipe and annulus flow, respectively. The reactor wall, the fuel tube lip, and the inflowing streams are held at the reactor's nominal operating temperature. Note that chemical reactions elevate temperatures within the reactor slightly above these boundary conditions. All six operating configurations listed in Table 2 are considered.

\subsection{Multiple Reaction Zones}

In the $2 \mathrm{D}$ simulations, a time-dependent problem is solved for the evolution of the reactor beginning from the initial conditions of the gas in the oxidizer stream. That the simulations achieve a steady state after 1-2 s of simulated time is evidence for the stability of the reactor. Usually, a conical reaction zone develops that rises from the fuel tube's lip to an apex approximately $1 \mathrm{~cm}$ above on the centerline. However, for the lowest temperature considered, $1200 \mathrm{~K}$, the reaction zone assumes the shape of a parabola of revolution that floats a few centimeters above the fuel tube and extends almost across the reactor's width.

The two types of reaction zones can be seen in Fig. 3 for two different temperatures in the 1:3 $\mathrm{F} / \mathrm{O}$ flow ratio configuration. The figure shows the first intermediates, $\mathrm{CH}_{3}$ and $\mathrm{NH}_{2}$, that occur from the decomposition of the fuels. The reaction zone for ammonia is collocated with that of methane to share the radical pool created by the more vigorous carbon chemistry.

It is convenient to use concepts from combustion science to describe the reaction zones even though they are not self-sustaining flames. Figure 3 (bottom series of images) shows that the "nonpremixed" zone lies at the thermodynamically optimal position on or near the stoichiometric line. Table 1 indicates that the combined mixture is very lean, with an $\mathrm{O}_{2}$ mole fraction 40 times that of $\mathrm{CH}_{4}$. Only a relatively small amount of the available oxygen must diffuse into the fuel stream to form a stoichiometric mixture. As a result the nonpremixed reaction zone lies near the fuel tube at the bottom of the reactor.

The "premixed" reaction lies much higher in the reactor where the two streams are nearly fully mixed. The simulation's fuel stream contains traces of argon to assess the progress of mixing. Figure 3 (rightmost images) shows that argon mixes to within $\pm 50 \%$ of its final concentration of $100 \mathrm{ppm}$ no sooner than $3 \mathrm{~cm}$ downstream from the fuel tube. The premixed reaction zone lies slightly above this point. 
It is presumed that reactors operating at below-flame temperatures achieve complete mixing before reacting, e.g. well-stirred reactors. Indeed, diffusion flames do not attain adiabatic premixed flame temperatures [21, p. 130], so it may be inferred that mixtures sustain reactions more effectively. The thick, premixed reaction zone that forms at lower temperatures evidently affords radicals long enough life to allow chain branching, whereas the thin, nonpremixed reaction zone requires higher temperatures to sustain a radical pool. When the nonpremixed reaction zone is feasible then it forms immediately on contact of the streams, thereby precluding the formation of a premixed reaction zone downstream.

\subsection{Comparison of Experiment with the 2D Simulation}

Figure 2 shows that the $2 \mathrm{D}$ simulation's predictions can be in good agreement with the measured NO outflow when the premixed reaction zone is active. The predictions lie on or near the measurements for the 1:3-1200 and 3:1-1300 (F/O flow ratio - temperature $\mathrm{K}$ ) configurations. However, in the 1:3-1300 case the simulation develops a nonpremixed reaction zone while the reactor apparently remains in the premixed mode. This suggests that the 1:3-1300 operating point lies near a stability limit for one or both of the reaction zones. Passing beyond a stability limit would account for the abrupt change in Fig. 2's trend of NO measurements for the 1:3 F/O flow ratio.

For the same reason several factors may be responsible for the discrepancy between measurement and prediction in the 1:3-1300 case. Stability limits are difficult to predict exactly because they are very sensitive. Small errors in chemical models may cause large errors in calculated inflection points, as for example extinction limits. Apparatus imperfections may favor one stable mode over another near a stability limit. Axisymmetric models cannot reproduce the asymmetric reaction zones which are typical for nearly unstable flames [22, pp. 171+]. Finally, hysteresis may occur while changing control points in a reactor, whereas the model calculations reinitialize from a nonreacting state.

When the nonpremixed reaction zone is active in both the simulation and the reactor then the predictions and measurements again are in good agreement. Figure 4, which repeats some data from Fig. 2, shows that predictions are consistently within $20 \%$ of the measurements for the $1500 \mathrm{~K}$ operating points. The degree of agreement is encouraging because reaction mechanisms have been developed from data for homogeneous mixtures and flame temperatures, which are environments quite different from this experiment. 


\subsection{Effect of Flow Ratio}

For the nonpremixed reaction zone that forms at higher temperatures, both the measurements and the predictions in Fig. 2 show a relationship between NO production and the F/O flow ratio. The generally good agreement in Fig. 4 provides a measure of confidence that this effect of mixing can be understood by examining the simulation results: the flow field and the reactions in it.

Figure 5 provides a detailed look at the reaction zone for low and high F/O flow ratios at 1500 $\mathrm{K}$. The reaction zone anchors slightly inside the fuel stream where the oxidizer is able to diffuse into comparatively slow-moving fluid along the lip of the fuel tube, which extends from 0.55 to 0.70 $\mathrm{cm}$. The actual reaction zone may dip slightly into the tube, but this cannot be determined from the present simulation which begins at the fuel tube's lip. This reaction zone differs from a typical diffusion flame's which would be anchored by a triple flame lifted off the lip. The models used in the simulation are capable of predicting a triple flame structure as can be seen in [6]. However, it is to be expected that the present reaction zone's anchoring differs from that of a flame because the reactor's feed streams are much hotter than ambient temperatures.

The salient features of the reaction zone in the high flow case are that it is more uniform from base to tip and it occurs at leaner conditions. The configurations of the experiment do not reveal whether this is due solely to the increased flow ratio, or occurs in concert with the greater dilution of the fuel stream by which the higher flow ratio is achieved.

To understand how the chemistry differs between the two reaction zones, reaction path diagrams were prepared by integrating the reaction flux of atomic nitrogen over the computational domain. Figure 6 shows the change in the reaction paths that results from increasing the fuel/oxidizer flow ratio from 1:3 to $3: 1$ at the same temperature, $1500 \mathrm{~K}$. Evidently a multiplicity of reaction paths are responsible for the increased NO outflow observed in Fig. 4. Some paths culminating in $\mathrm{HNO} \rightarrow \mathrm{NO}$ are enhanced, while many that consume NO are decreased.

That so many paths are affected by the flow ratio suggests that this is caused by a major alteration of the nonpremixed reaction zone. It has been seen in Fig. 5 that the site for nitrogen reactions shifts toward the lean side of the stoichiometric surface when the flow ratio increases. Roughly speaking, this favors the formation of a product that contains oxygen, NO, over one that does not, $\mathrm{N}_{2}$. A fairly complete picture can be obtained by considering the five most altered paths 
into or out of $\mathrm{NO}$ which are responsible for most of the increased production.

1. $\mathrm{HNO} \rightarrow \mathrm{NO}$ (increased): From Fig. 6 the path $\mathrm{NH}_{2} \rightarrow$ HNO begins the primary route leading to enhanced NO production from nitroxyl. The reaction $\mathrm{NH}_{2}+\mathrm{O} \rightleftharpoons \mathrm{HNO}+\mathrm{H}$ accounts for all of this path. The forward direction is enhanced when more amidogen is found on the lean side of the stoichiometric surface where atomic oxygen is prevalent from chain branching.

2. $\mathrm{NO} \rightarrow \mathrm{N}_{2}$ (decreased): Roughly half of the flux through this path is caused by the reaction $\mathrm{NH}_{2}+\mathrm{NO} \rightleftharpoons \mathrm{N}_{2}+\mathrm{H}_{2} \mathrm{O}$. On the lean side of the stoichiometric surface this competes unfavorably with the reaction noted above, $\mathrm{NH}_{2}+\mathrm{O} \rightleftharpoons \mathrm{HNO}+\mathrm{H}$. Another contributor to the path $\mathrm{NO} \rightarrow \mathrm{N}_{2}$ is $\mathrm{NH}+\mathrm{NO} \rightleftharpoons \mathrm{N}_{2}+\mathrm{OH}$, as discussed below.

3. $\mathrm{NH} \rightarrow \mathrm{NO}$ (inc.) and $\mathrm{NO} \rightarrow \mathrm{N}_{2} \mathrm{O}$ (dec.): Like the preceding pair of paths, these result from reactions that compete for the same nitrogenous reactant, in this case imidigen. Shifting the reaction zone to an oxygen-rich mixture promotes $\mathrm{NH}+\mathrm{O} \rightleftharpoons \mathrm{NO}+\mathrm{H}$ which in turn suppresses $\mathrm{NH}+\mathrm{NO} \rightleftharpoons \mathrm{N}_{2} \mathrm{O}+\mathrm{H}$ and $\rightleftharpoons \mathrm{N}_{2}+\mathrm{OH}$. There is also less $\mathrm{NH}$ to share because as noted $\mathrm{NH}_{2} \rightarrow \mathrm{NH}$ competes unfavorably with $\rightarrow \mathrm{HNO}$ in an oxygen-rich mixture.

4. $\mathrm{NO} \rightarrow \mathrm{HCN}$ (dec.): This path is due to reactions with $\mathrm{CH}_{2}$ and $\mathrm{HCCO}$ which are found only on the rich side of the stoichiometric surface.

In summary, the shift in the location of the species $\mathrm{NH}_{i}, i=1,2$, to lean mixtures increases production of $\mathrm{NO}$ through reactions with $\mathrm{O}$, and reduces their availability to consume $\mathrm{NO}$ in other reactions. Other factors such as the decreased availability of carbonaceous species to react with NO further contribute to the greater outflow of nitric oxide.

\section{The Zwietering Model}

The $2 \mathrm{D}$ simulation is very demanding computationally and it is of interest whether models with a simplified description of the flow characteristics can provide an estimate of the effect of mixing on the present chemistry. A simple, qualitative method was proposed by Zwietering [23] to describe mixing effects in chemically reacting systems. The Zwietering model describes macro-mixing in a reactor with two unmixed feed-streams, using a non-ideal plug-flow reactor configuration. In this 
approach typically the secondary feed-stream is uniformly distributed along the primary stream over a mixing time, $\tau_{m}$. In previous work this approach has been used with some success to describe the effect of mixing on reburning [24] and on the Thermal De- $\mathrm{NO}_{x}$ process [7]. In our present context we assume an exponential entrainment of the oxidizer stream into the fuel stream, i.e. the rate of change in mass flow of the fuel stream due to entrainment is given by

$$
\frac{d \dot{m}_{\text {fuel }}}{d t}=k \dot{m}_{\text {oxid }}
$$

where $k$ is a rate constant for the entrainment, calculated from an estimate of the mixing time,

$$
k=\frac{\ln \left(\dot{m}_{\text {oxid }, 0} / \dot{m}_{\text {oxid }, \tau_{m}}\right)}{\tau_{m}}
$$

A comparison between the experimental results and modeling predictions allows an assessment of the predictive capabilities of the Zwietering approach. The entrainment rate of the oxidizer stream into the fuel stream is calculated based on an estimation of the time required to obtain 95\% mixing of the two flows. This information was obtained from the concentration of the argon tracer in the 2D simulations. The mixing time was defined as the time it takes for a particle on the fuel stream centerline to reach the point where the argon concentration has diffused away down to $105 \%$ of its final concentration. Mixing depends on the flow configuration and the temperature. The following mixing times and centerline positions were estimated from the 2D simulation: 1:3 flow ratio $(1200 \mathrm{~K}: 1.5 \mathrm{~s}, 6.8 \mathrm{~cm} ; 1300 \mathrm{~K}: 1.3 \mathrm{~s}, 6.2 \mathrm{~cm} ; 1500 \mathrm{~K}: 1.03 \mathrm{~s}, 5.9 \mathrm{~cm}), 1: 1$ flow ratio $(1500 \mathrm{~K}: 0.67 \mathrm{~s}, 5.7 \mathrm{~cm})$, and 3:1 flow ratio $(1300 \mathrm{~K}: 0.37 \mathrm{~s}, 4.8 \mathrm{~cm} ; 1500 \mathrm{~K}: 0.31 \mathrm{~s}, 4.6 \mathrm{~cm})$. For extrapolation to other conditions we assumed the mixing time to scale with temperature as $\mathrm{T}^{-1.75}$.

Figure 2 compares the experimental results with predictions by the Zwietering model. The results show that the Zwietering model captures the essential features of the $\mathrm{NH}_{3}$ oxidation behavior. The crossing point temperature, where the results begin to deviate from plug-flow behavior, is predicted correctly for all configurations. For the $3: 1$ and 1:1 flow configurations the effect of mixing at high temperatures is described well, while a considerable deviation is observed above $1350 \mathrm{~K}$ for the 1:3 configuration.

These results, together with those of Fig. 5, provide some idea of the strengths and limitations of the Zwietering approach. It appears to be suitable for describing the behavior of the nonpremixed system as long as the radial concentration gradients in the reaction zone are not too large. However, if a fast reaction occurs in the mixing region, with local high concentrations of radicals, 
the Zwietering approach is no longer appropriate. For this reason it is not suitable to describe nonpremixed systems where ignition occurs; for such systems a more advanced reactor concept is required, perhaps similar to the Two-Stage Lagrangian model [25] developed for turbulent flows.

\section{Conclusion}

A combined experimental and modeling study is performed of the effects of mixing on ammonia oxidation at temperatures below those in self-sustaining flames. Dilute streams of methane-ammonia and oxygen-water are commingled in an isothermal environment. It is found that, as in flames, the NO production is sensitive to mixing. At low temperatures only a premixed reaction zone is viable which produces high levels of NO. At higher temperatures a nonpremixed reaction zone forms where NO production is much less. The crossover point between the two types of reaction zones appears to be governed by a stability phenomenon that also depends on the relative velocities and concentrations of the fuel and oxidizer streams. The ratio of flow velocities also affects the NO production from the nonpremixed reaction zone. For increased velocities of the fuel stream the reaction zone moves toward the lean side of the stoichiometric surface where the greater likelihood of reaction with oxygen species increases the selectivity of NO as a final product. A direct numerical simulation is required to predict the behavior over the full range of conditions investigated experimentally, while a simple Zwietering model captures the essential features as long as the radial gradients are not too steep.

\section{Acknowledgments}

The work of Grcar, Bell, and Day was supported by the Applied Mathematical Sciences Program of the DOE Office of Mathematics, Information, and Computational Sciences, under contract DEAC03-76SF00098.

The work of Glarborg, Loren, and Jensen was supported by the research program CHEC (Combustion and Harmful Emission Control), which is co-funded by the Danish power companies Elsam and Energi E2, and by the Danish Ministry of Energy. 


\section{References}

[1] Glarborg, P., Jensen, A., and Johnsson, J. E., Prog. Energy Combust. Sci., 29:89-113 (2003).

[2] Miller, J. A. and Glarborg, Int. J. Chem. Kinet., 31:757-765 (1999).

[3] Schmidt, C. C. and Bowman, C. T., Combust. Flame, 127:1958-1970 (2001).

[4] Skreiberg, O., Kilpinen, P., and Glarborg, P., Combust. Flame, 136:501-518 (2004).

[5] Sarofim, A. F., Williams, G. C., Modell, M., and Slater, S. M., AIChE Symp. Ser., 71(148):51-61 (1975).

[6] Sullivan, N., Jensen, A., Glarborg, P., Day, M. S., Grcar, J. F., Bell, J. B., Pope, C., and Kee, R. J., Combust. Flame, 131:285-298 (2002).

[7] Røjel, H., Jensen, A., Glarborg, P., and Dam-Johansen, K., Ind. Eng. Chem. Res., 39:3221-3232 (2000).

[8] Lutz, A. E., Kee, R. J., and Miller, J. A., "SENKIN: A fortran program for predicting homogeneous gas phase chemical kinetics with sensitivity analysis," Sandia Report No. SAND87-8248.

[9] Glarborg, P., Alzueta, M. U., Dam-Johansen, K., and Miller, J. A., Combust. Flame, 115:1-27 (1998).

[10] Miller, J. A., Smooke, M. D., Green, R. M., and Kee, R. J., Combust. Sci. Tech., 34:149-176 (1983).

[11] Glarborg, P., Miller, J. A., and Kee, R. J., Combust. Flame, 65:177-202 (1986).

[12] Miller, J. A. and Bowman, C. T., Prog. Energy Combust. Sci., 15(4):287-338 (1989).

[13] Branch, M. C., Kee, R. J., and Miller, J. A., Combust. Sci. Tech., 29:147-165 (1982).

[14] Smooke, M. D., Ern, A., Tanoff, M. A., Valdati, B. A., Mohammed, R. K., Marran, D. F., and Long, M. B., Proc. Combust. Inst., 26:2161-2170 (1996).

[15] Majda, A. and Sethian, J. A., Combust. Sci. Technol., 42:185-205 (1985). 
[16] Rehm, R.G. and Baum, H.R., N. B. S. J. Res., 83:297-308 (1978).

[17] Day, M. S. and Bell, J. B., Combust. Theory Modelling, 4:535-556 (2000).

[18] Kee, R. J., Dixon-Lewis, G., Warnatz, J., Coltrin, M. E., and Miller, J. A., "A FORTRAN computer code package for the evaluation of gas-phase multicomponent transport properties," Sandia National Laboratories Report No. SAND86-8246.

[19] Kee, R. J., Ruply, R. M., Meeks, E., and Miller, J. A., "Chemkin-III: A FORTRAN chemical kinetics package for the analysis of gas-phase chemical and plasma kinetics," Sandia National Laboratories Report No. SAND96-8216.

[20] Bell, J. B., Day, M. S., Grcar, J. F., Bessler, W. G., Schultz, C., Glarborg, P., and Jensen, A. D., Proc. Combust. Inst., 29:2195-2202 (2002).

[21] Warnatz, J., Maas, U., and Dibble, R. W., Combustion (3rd ed), Springer-Verlag, Berlin, 2001.

[22] Glassman, I., Combustion (third ed), Academic Press, 1996.

[23] Zwietering, T. N., Chem. Eng. Sci., 11:1-15 (1959).

[24] Alzueta, M. U., Bilbao, R., Millera, A., Glarborg, P., Østberg, M., and Dam-Johansen, K., Energy Fuels, 12:329-338 (1998).

[25] Broadwell, J. E. and Lutz, J. E., Combust. Flame, 114:319-335 (1998). 


\section{Tables}

Table 1: Compositions of the fuel and oxidizer streams as mole fractions of the combined fueloxidizer inflow of $2 \mathrm{~L} / \mathrm{min}$.

\begin{tabular}{l|c|c|} 
species & fuel & oxidizer \\
\hline $\mathrm{CH}_{4}$ & $1.0 \mathrm{e}-3$ & \\
$\mathrm{NH}_{3}$ & $3.0 \mathrm{e}-4$ & \\
$\mathrm{O}_{2}$ & & $4.0 \mathrm{e}-2$ \\
$\mathrm{H}_{2} \mathrm{O}$ & & $2.0 \mathrm{e}-2$ \\
$\mathrm{~N}_{2}$ & balance & balance \\
\hline
\end{tabular}

Table 2: Reactor configurations for which simulations are performed and their predicted NO ppm in the outflows.

\begin{tabular}{c|ccc|}
$\mathrm{F} / \mathrm{O}$ & $1200 \mathrm{~K}$ & $1300 \mathrm{~K}$ & $1500 \mathrm{~K}$ \\
\hline $1: 3$ & 76.0 & 80.5 & 84.9 \\
$1: 1$ & & & 121.8 \\
$3: 1$ & & 124.8 & 150.6 \\
\hline
\end{tabular}




\section{List of Figures}

1 Schematic for the dimensions of the quartzware where the reactions occur. . . . . 16

2 Influence of temperature and fuel/oxidizer flow ratios on the conversion of $\mathrm{NH}_{3}$ to NO in the reactor, compared with predictions for a plug-flow reactor [8], a simple mixing model (Zwietering), and from 2D simulations. Experimental measurements of $\mathrm{NO}$ are $\pm 3 \%$, and reactor isothermicity is $\pm 13 \mathrm{~K} \ldots \ldots \ldots \ldots$

3 Calculated temperatures and selected mole fractions in the first $6 \mathrm{~cm}$ at the base of the reactor. Two operating conditions are shown to illustrate the qualitative difference between the reactor's two operating modes. Low temperatures (top) have a detached, parabolic, premixed reaction zone. In contrast, much like a diffusion flame, high temperatures (bottom) have an attached, conical, nonpremixed reaction zone at the surface of stoichiometric mixture. A trace amount of argon in the fuel stream almost completely diffuses into the oxidizer stream when the flow reaches about $4-5 \mathrm{~cm}$ into the reactor (right top and bottom) . . . . . . . . . . 17

4 Measured and predicted NO for various flow rates at 1500 K. . . . . . . . . 18

5 Calculated mole fractions above the fuel tube at the base of the reactor. Two operating points are shown at the same temperature, $1500 \mathrm{~K}$, to illustrate the qualitative effect of a greater fuel/oxidizer flow ratio on the reactor's nonpremixed reaction zone. In all the figures the superimposed dashed line indicates the stoichiometric surface. . 18

6 Difference in nitrogen reaction paths for reactor configurations with low 1:3 and high 3:1 fuel/oxidizer flow ratios at $1500 \mathrm{~K}$. The width of an arrow indicates the amount of change in the reaction flux of atomic nitrogen between the species at its head and tail. Only changes at least $1 \%$ of the greatest are shown. Blue indicates paths that shrink with increased flow ratio; enhanced paths are red. . . . . . . . . . . . . 19 


\section{Figures}

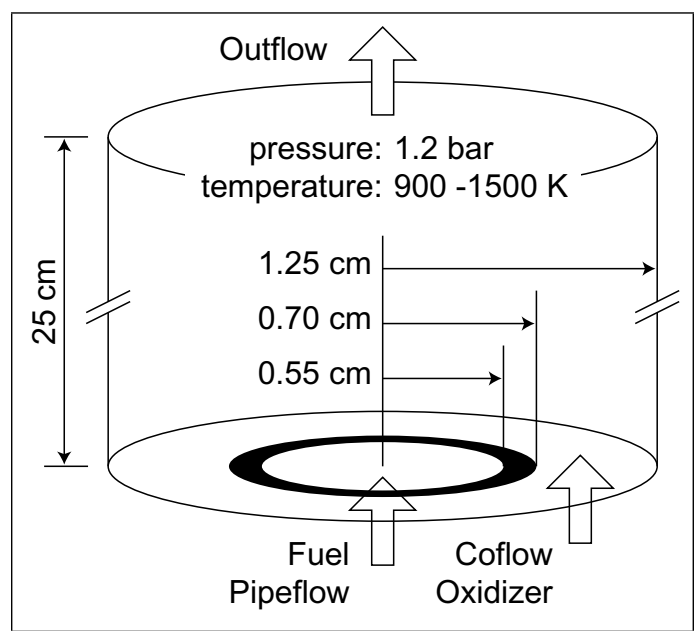

Figure 1: Schematic for the dimensions of the quartzware where the reactions occur.

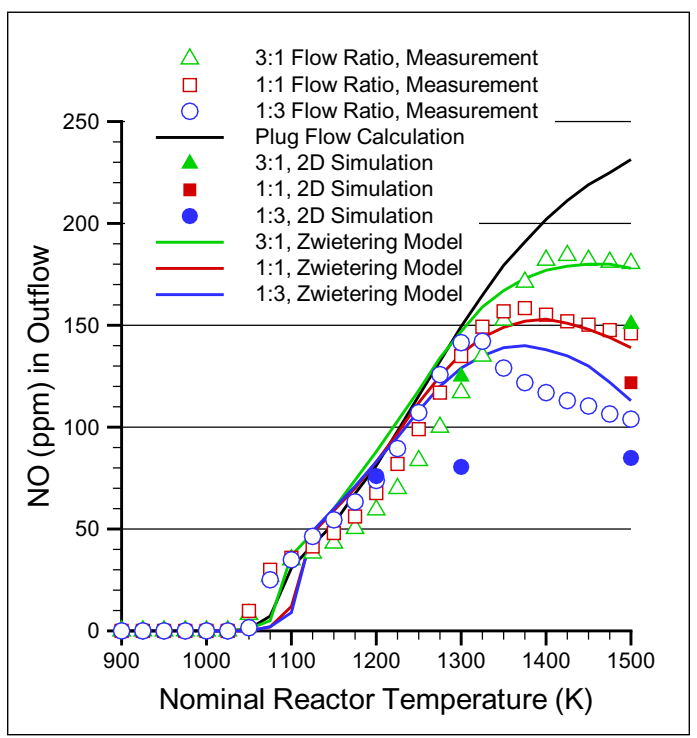

Figure 2: Influence of temperature and fuel/oxidizer flow ratios on the conversion of $\mathrm{NH}_{3}$ to $\mathrm{NO}$ in the reactor, compared with predictions for a plug-flow reactor [8], a simple mixing model (Zwietering), and from 2D simulations. Experimental measurements of $\mathrm{NO}$ are $\pm 3 \%$, and reactor isothermicity is $\pm 13 \mathrm{~K}$. 


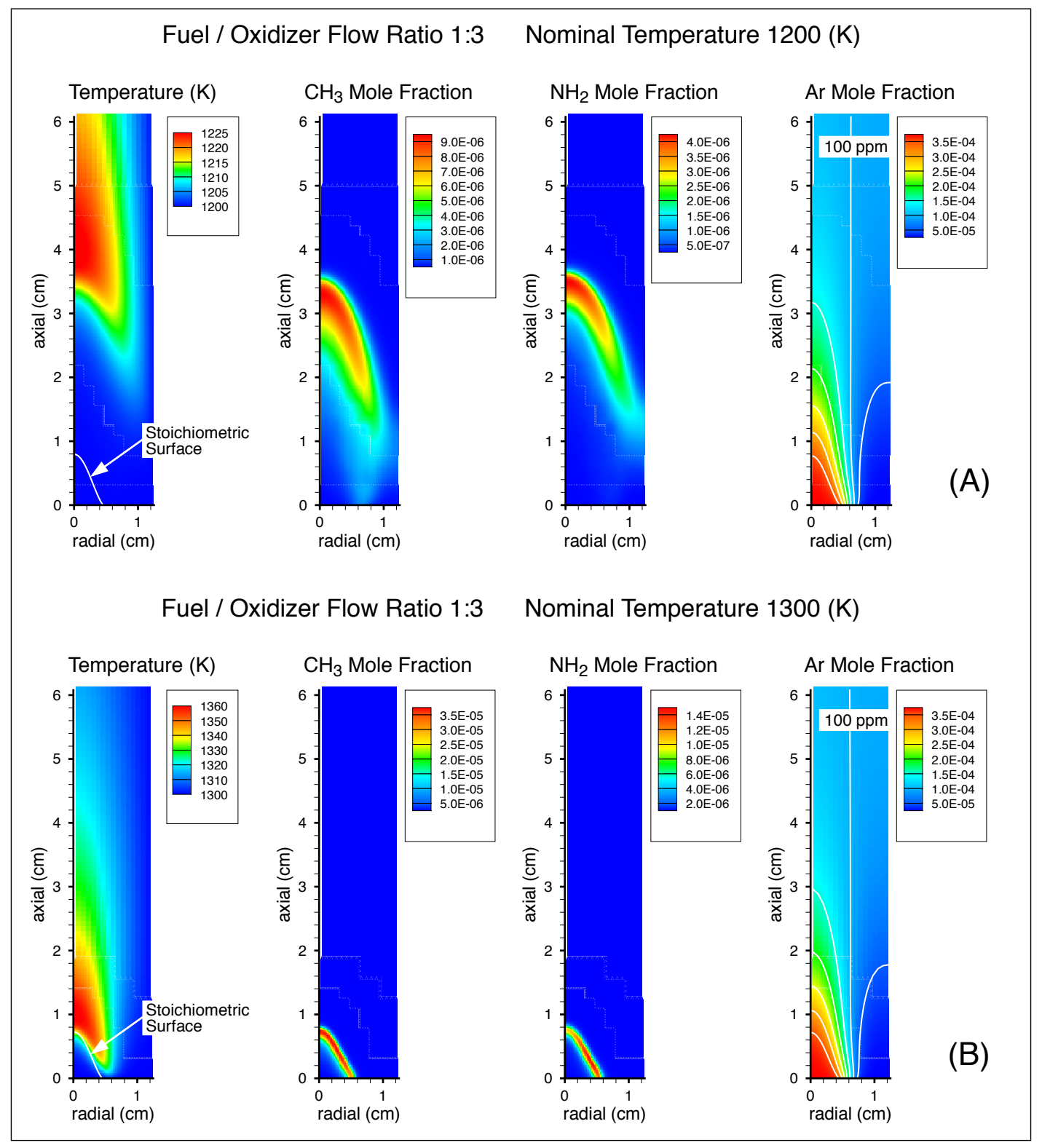

Figure 3: Calculated temperatures and selected mole fractions in the first $6 \mathrm{~cm}$ at the base of the reactor. Two operating conditions are shown to illustrate the qualitative difference between the reactor's two operating modes. Low temperatures (top) have a detached, parabolic, premixed reaction zone. In contrast, much like a diffusion flame, high temperatures (bottom) have an attached, conical, nonpremixed reaction zone at the surface of stoichiometric mixture. A trace amount of argon in the fuel stream almost completely diffuses into the oxidizer stream when the flow reaches about 4-5 cm into the reactor (right top and bottom). 


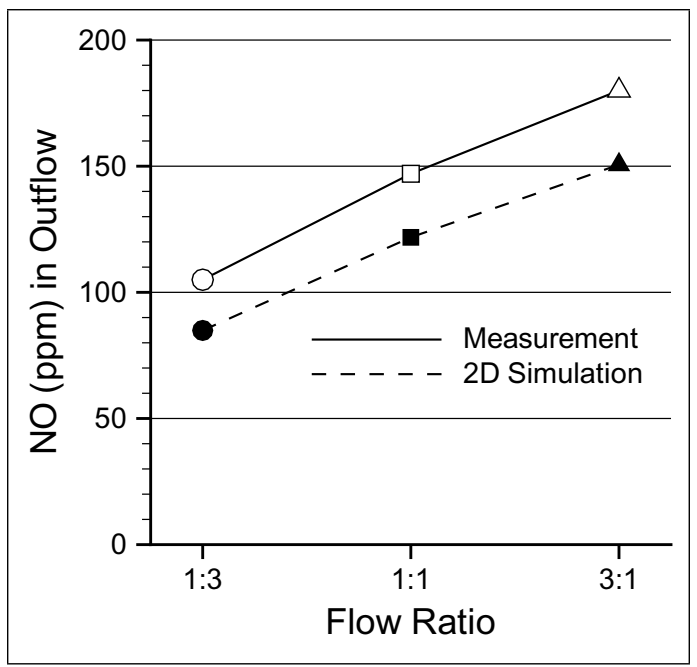

Figure 4: Measured and predicted NO for various flow rates at $1500 \mathrm{~K}$.

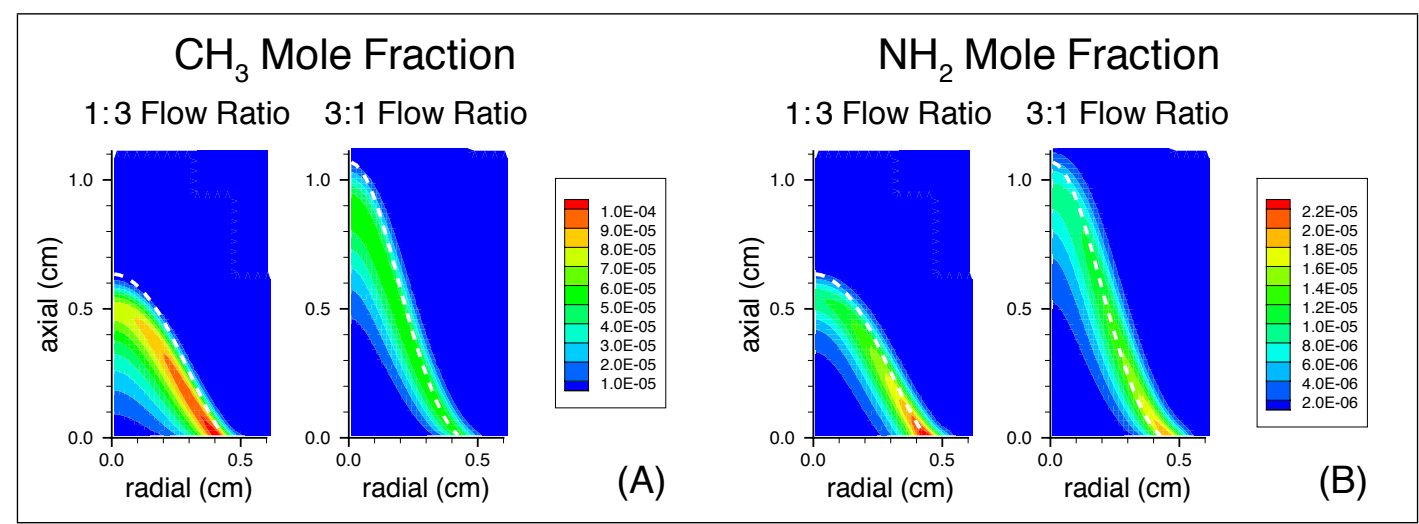

Figure 5: Calculated mole fractions above the fuel tube at the base of the reactor. Two operating points are shown at the same temperature, $1500 \mathrm{~K}$, to illustrate the qualitative effect of a greater fuel/oxidizer flow ratio on the reactor's nonpremixed reaction zone. In all the figures the superimposed dashed line indicates the stoichiometric surface. 


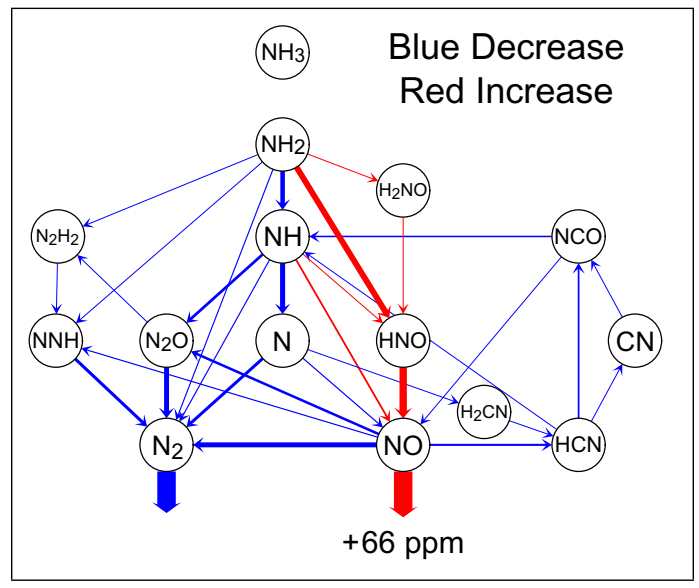

Figure 6: Difference in nitrogen reaction paths for reactor configurations with low 1:3 and high 3:1 fuel/oxidizer flow ratios at $1500 \mathrm{~K}$. The width of an arrow indicates the amount of change in the reaction flux of atomic nitrogen between the species at its head and tail. Only changes at least 1\% of the greatest are shown. Blue indicates paths that shrink with increased flow ratio; enhanced paths are red. 